\title{
ANALISIS FAKTOR DETERMINAN EFISIENSI NILAI BED OCCUPANCY RATIO: FISHBONE ANALYSIS
}

\author{
Tri Lestari ${ }^{1 *}$, Isa Tri Wahyuni ${ }^{1}$ \\ ${ }^{1,2}$ STIKes Mitra Husada Karanganyar \\ *email: trilestari.mhk@gmail.com
}

\begin{abstract}
One indicator of the fulfillment of health services to the community, especially in hospitals, was the calculation of the Bed Occupancy Rate (BOR). Factors that caused inefficient $B O R$ need to be analyzed. This study aimed to analyze the factors causing inefficient BOR through fishbone analysis.

This study was a qualitative descriptive study conducted at Surakarta City Hospital in February - June 2019. The subjects of this study were medical record officers, inpatient registration, reporting, ward head, doctor providing services. Data is taken by interview method and observation checklist. Data were analyzed using fishbone analysis

The results of this study indicate that the factors that cause inefficient BOR values are Method (doctor's visit schedule has not been obeyed and SOP related to CP has not been implemented), Machine (lack of TT availability, system error, and meeting forums are less effective ), Man (human resources) (lack of neurosurgeons, doctors' uncertainty in visiting, parttime doctors), Materials (materials) (recapitulation data is not available LD data items, SHRI only contains a 1 day resume of activities in the form of numbers ), Money (funds) (There is no funding for rewarding), environment (damaged road access and less strategic location).

Fishbone diagram inefficient BOR values are caused by the Man factor (human resources) and the Machine factor (machine).
\end{abstract}

Keywords: Bed Occupncy Rate, Fishbone Analysis

Salah satu indikator terpenuhinya layanan kesehatan kepada masyarakat khususnya di Rumah sakit adalah dengan perhitungan Bed Occupancy Rate (BOR). Faktor penyebab BOR tidak efisien perlu dilakukan analisis. Penelitian ini bertujuan untuk menganalisis faktor penyebab BOR tidak efisien melalui analisis fishbone.

Penelitian ini merupakan penelitian deskriptif kualitatif yang dilakukan di RSUD Kota Surakarta pada bulan Februari - Juni 2019. Subjek penelitian ini adalah petugas rekam medis, pendafataran rawat inap, pelaporan, kepala bangsal, dokter pemberi layanan. Data diambil dengan metode wawancara dan checklist observasi. Data dianalisis dengan menggunakan fishbone analysis.

Hasil penelitian ini menunjukkan bahwa faktor-faktor yang menyebabkan nilai BOR tidak efisien adalah Method (metode) (jadwal visit dokter belum dipatuhi dan SOP terkait CP belum terimplementasi), Machine (mesin) (kekurangan ketersedian TT, system error, dan forum rapat kurang efekif), Man (sumber daya manusia) (kurang dokter spesialis bedah syaraf, ketidakpastian dokter dalam melakukan kunjungan visit, dokter part time), Materials (bahan) (data rekapitulasi tidak tersedia item data LD, SHRI hanya berisi resume kegiatan 1 hari dalam bentuk angka), Money (dana) (Belum ada dana untuk pemberian reward), lingkungan (akses jalan rusak dan lokasi kurang stategis).

Diagram fishbone Nilai BOR tidak efisien terbanyak disebabkan oleh faktor Man (sumber daya manusia) dan faktor Machine (mesin).

Kata kunci: Bed Occupancy Rate, Analisis Fishbone 


\section{PENDAHULUAN}

Rumah sakit merupakan salah satu upaya yang dapat meningkatkan derajat kesehatan manusia yang bersifat kuratif dan rehabilitatif. Rasio tempat tidur merupakan indikator terpenuhi atau tidaknya kebutuhan masyarakat terhadap layanan kesehatan rujukan atau perorangan di suatu wilayah (Kemenkes, 2018). Pendayagunaan tempat tidur di rumah sakit seharusnya efisien dari aspek ekonomi maupun aspek medis (Susilo \& Nopriadi, 2012). Salah satu indikator efisiensi layanan RS adalah dengan menghitung rasio hunian tempat tidur atau Bed Occupancy Rate (BOR) dari RS (Sidiq \& Afrina, 2017). Faktor-faktor yang mempengaruhi rendahnya BOR adalah kurangnya sumber daya manusia, sarana prasarana yang kurang memadai, prosedur pengobatan yang belum memenuhi standard, belum menggunakan billing system, banyaknya rumah sakit (RS) kompetitor yang berdekatan (Nofitasari, 2017). BOR yang rendah dapat diartikan sebagai rendahnya layanan kesehatan masyarakat sehingga diperlukan metode analisis yang tepat untuk mengetahui faktor-faktor penyebab rendahnya BOR di RS.

\section{Standard World Health}

Organization (WHO) untuk rasio tempat tidur adalah 1 tempat ridur untuk 1.000 penduduk. Rasio tempat tidur di rumah sakit di Indonesia dari tahun 2013-2017 sekitar 1 per 1.000 penduduk. Jumlah tempat tidur di Indonesia sudah tercukupi menurut WHO. Rasio tempat tidur ini tidak mencukupi apabila diuraikan di setiap provinsi di Indonesia karena masih ada provinsi yang memiliki rasio tempat tidur <1 (Kemenkes, 2018). Berdasarkan survei pendahuluan dari laporan indikator pelayanan rawat inap di Rumah Sakit Umum Daerah (RSUD) Kota Surakarta diketahui nilai BOR selama kurun waktu 10 tahun memiliki nilai yang fluktuatif yaitu dapat terlihat pada gambar 1 .
Berdasarkan gambar di atas BOR RSUD Surakarta menurut nilai ideal BarberJohnson (75-85\%) masih dibawah nilai ideal. Semakin rendah nilai BOR berarti semakin sedikit temapat tidur (TT) yang digunakan untuk merawat pasien dibandingkan dengan TT yang telah disediakan. Dengan kata lain, jumlah pasien yang sedikit ini bisa menimbulkan kesulitan pendapatan ekonomi bagi pihak rumah sakit (Sudra, 2010).

Salah satu analisis untuk mengetahui faktor-faktor yang menyebabkan rendahnya BOR adalah dengan menggunakan analisis tulang ikan (Fishbone). Keuntungan penggunaan analisis fishbone salah satunya adalah memastikan pasien mendapatkan perawatan terbaik, ada kebutuhan untuk menganalisis dan mengubah praktik keperawatan, mengkaji bagaimana menggunakan analisis tulang ikan untuk mengidentifikasi penyebab masalah, yang mengarah ke solusi dan rencana tindakan, sehingga dapat membantu staf untuk membuat perubahan pada layanan mereka untuk memberi manfaat bagi pasien dan staf (Phillips \& Simmonds, 2013).

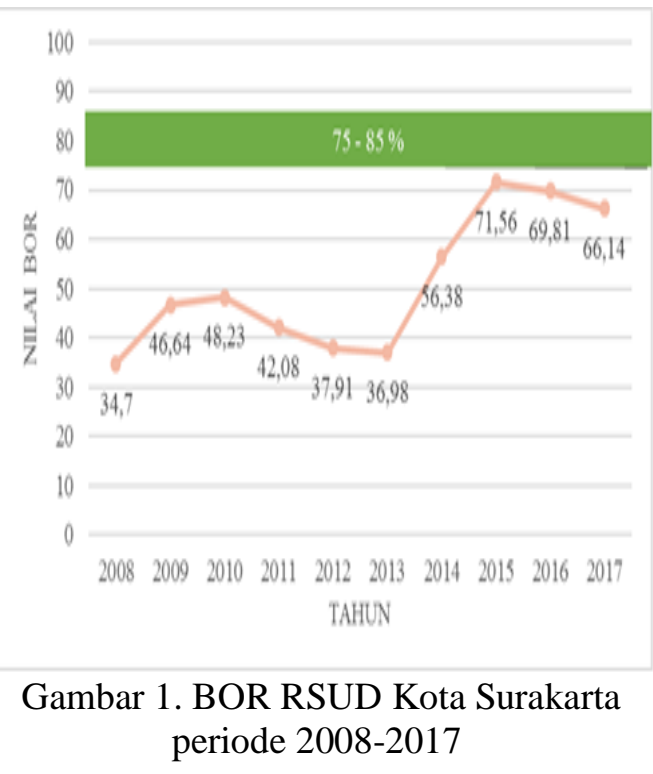




\begin{abstract}
Berdasarkan penelitian sebelumnya dan fakta yang ada menyatakan bahwa analisis fishbone dapat digunakan untuk menganalisis suatu layanan kesehatan dengan mengidentifikasi masalah yang ada sehingga penulis ingin mengetahui "Faktor Deteminan Yang Mempengaruhi Ketidakefektifan Nilai Bed Occupancy Rate Dengan Menggunakan Analisis Fishbone"
\end{abstract}

\section{METODE PENELITIAN}

Penelitian ini menggunakan pendekatan Deskriptif Kualitatif. Tempat penelitian ini adalah di RSUD Kota Surakarta. Penelitian ini dilakukan pada bulan Februari - Juni 2019. Subjek dalam penelitian ini adalah petugas rekam medis bagian pendaftaran rawat inap dan pelaporan, 2 kepala ruang bangsal, dan dokter pemberi pelayanan asuhan serta kepala komite medik KMKB di Rumah Sakit Umum Daerah Kota Surakarta. Objek dalam penelitian ini adalah sensus harian rawat inap, dan laporan indikator rawat inap di Rumah Sakit Umum Daerah Kota Surakarta.

Pengumpulan data menggunakan teknik triangulasi data dengan mengumpulkan data kualitatif dan kuantitatif. Sensus harian rawat inap menggunakan instrumen berupa pedoman wawancara yang berisi daftar pertanyaan yang akan digunakan untuk mengetahui faktor - faktor yang mempengaruhi BOR dan check list observasi. Data kualitatif wawancara juga menggunakan instrumen berupa alat perekam untuk mempermudah penulis menuliskan kembali pernyataan responden. Data kuantitatif diperoleh dari hasil perincian data Rekapitulasi Laporan RL 1.2 di Rumah Sakit Umum Daerah Kota Surakarta.

Data yang diperoleh kemudian dirangkum, dipilih hala-hal pokok dan difokuskan pada hal-hal yang penting yang mempengaruhi faktor penyebab ketidakefektifan nilai BOR. Data selanjutnya disajikan dalam bentuk naratif dalam analisis fishbone. Kemudian data dilakukan penarikan kesimpulan.

\section{HASIL}

Hasil penelitian ini didapatkan data bahwa penyebab BOR tidak efisien disebabkan oleh 6 unsur yaitu metode (Method), mesin (machine), sumber daya manusia (man), bahan (materials) dan dana (money) serta lingkungan. Keenam unsur tersebut dapat dijelaskan pada tabel 1.

Tabel 1 Faktor Efisiensi BOR

\begin{tabular}{|c|c|c|}
\hline Aspek & $\begin{array}{l}\text { Faktor penyebab tidak } \\
\text { efisien nilai BOR }\end{array}$ & Pernyataan \\
\hline \multirow[t]{2}{*}{$\begin{array}{l}\text { Man } \\
\text { (Sumber } \\
\text { Daya } \\
\text { Manusia) }\end{array}$} & $\begin{array}{l}\text { Ketidakpastian dokter } \\
\text { dalam melakukan } \\
\text { kunjungan visit }\end{array}$ & $\begin{array}{l}\text { "Jam visit ditentukan jam } 08.00-14.00 \text {..... Kendala } \\
\text { seperti pelayanan poli atau jadwal mendadak ditempat } \\
\text { lain sehingga menyebabkan visit molor siang atau } \\
\text { bahkan sore" (R5.27.02.2019) }\end{array}$ \\
\hline & $\begin{array}{l}\text { Kurangnya dokter } \\
\text { spesialis bedah syaraf }\end{array}$ & $\begin{array}{l}\text { "Penyebab pasien dirujuk karena kondisi pasien, tidak } \\
\text { adanya dokter spesialis kususnya spesialis bedah } \\
\text { syaraf....." (R6.28.02.2019) }\end{array}$ \\
\hline $\begin{array}{l}\text { Mechine } \\
\text { (Mesin) }\end{array}$ & $\begin{array}{l}\text { Kekurangan ketersedian } \\
\text { TT }\end{array}$ & $\begin{array}{l}\text { "Fasilitas yang kurang memadai sehingga ada } \\
\text { beberapa yang dirujuk karena kurangnya fasilitas } \\
\text { tersebut. Contohnya TT penuh pada bangsal dewasa } \\
\text {..." (R2.25.02.2019) }\end{array}$ \\
\hline
\end{tabular}


efekif

Sistem eror dan tidak ada kebijakan pendaftaran manual beberapa perawat dan dokter .....t" (R4.26.02.2019)

"Rapat rutin dilakukan perbulan untuk penyampaian laporan hasil, namun dokter tidak semua hadir. Hanya dihadiri oleh kepala unit saja, ..." (R5.25.03.2019)

"Sistem pendaftaran pasien dengan SIMRS Pillar Hospital, sudah cukup mendukung pelayanan namun ada pernah juga terjadi eror ....." (R1.25.02.2019) "Pillar untuk melakukan pengolahan data statistik belum bisa hanya menyediakan sumber data saja..." (R2.25.02.2019)

$\begin{array}{ll}\text { Methode } & \text { Jadwal visit dokter } \\ \text { (Metode) } & \text { belum dipatuhi }\end{array}$

"Jam visit per dokter belum diatur, tetapi untuk jadwal visit sudah yaitu dari jam 08.00 - jam 14.00. Jadi dokter ada yang visit sebelum pelayanan poli, dan ada juga yang visit siang jam 14.00 selesai jam 15.00 jika pasien banyak. .." (R4.26.02.2019)

"Visit dokter beda - beda ada yang pagi jam 07.00 ada yang siang jam siang waktu pertukaran shif. .." (R3.26.02.2019)

Ada SOP terkait CP tetapi belum terimplementasi

“..... Terkait CP sini sudah ditetapkan adanya CP walaupun belum menyeluruh semua penyakit" (R4.26.02.2019)
“... CP sudah ada walaupun belum semua kasus namun dalam implementasi ada beberapa dokter yang tidak mematuhi aturan CP tersebut untuk alasannya secara medis konfirmasi ke dokter yang bersangkutan saja. Apabila dicurigai Fraud maka pihak manajemen yang akan turun tangan" (R3.26.02.2019)

“.... Untuk CP kemarin waktu akreditasi sudah ada team yang membuat. Namun untuk penerapannya belum bisa dilakukan karena kami belum menerima sosialisasi dan protap yang mengatur terkait CP" (R5.27.03.2019)

\begin{tabular}{ll}
\hline $\begin{array}{l}\text { Materials } \\
\text { (Bahan) }\end{array}$ & Data rekapitulasi tidak \\
tersedia item data LD
\end{tabular}
“.....rekapitulasi sensus yang terdiri dari item data jumlah hari, TT, pasien masuk, pasien pulang hidup, pasien keluar mati (> dan< 48 jam), hari perawatan, dan tidak ada ouput LD" (R2.25.02.2019)

SHRI hanya berisi "Dari sensus yang terkumpul pada setiap bangsal per resume kegiatan 1 hari hari akan diolah pada setiap bulan ..” (R2.25.02.2019) dalam bentuk angka

\begin{tabular}{|c|c|c|}
\hline \multirow[t]{2}{*}{ Lingkungan } & $\begin{array}{l}\text { Akses jalan rusak dan } \\
\text { masih dalam tahap } \\
\text { pembangunan }\end{array}$ & $\begin{array}{l}\text { "... dikarenakan jalan rusak, tempat kita harus masuk } \\
\text { di gang kecil. Sehingga pasien memilih ke RS yang } \\
\text { ditepi jalan.” (R1.25.02.2019) } \\
\text { ".. akses jalan yang lagi tahap pembangunan.” } \\
\text { (R4.26.02.2019) }\end{array}$ \\
\hline & $\begin{array}{l}\text { Lokasi kurang strategis } \\
\text { karena jarak dari kota } 21 \\
\text { km dengan jarak tempuh } \\
45 \text { menit }\end{array}$ & $\begin{array}{l}\text { “... jarak tempuh yang jauh bagi yang di pusat kota } \\
\text { sekitar } 21 \mathrm{~km} \text {, kira - kira } 45 \text { menit jika kondisi lalu } \\
\text { lintas lancar.." (R5.27.02.2019) }\end{array}$ \\
\hline $\begin{array}{l}\text { Money } \\
\text { (Dana) }\end{array}$ & $\begin{array}{l}\text { Belum ada dana untuk } \\
\text { pemberian reward }\end{array}$ & $\begin{array}{l}\text { "Belum dianggarkan dana untuk pemberian reward. } \\
\text { Tetapi rumah sakit sudah menerapkan program } \\
\text { "Bintang Visit Dokter" ....." (R4.26.02.2019) }\end{array}$ \\
\hline
\end{tabular}

Sumber: Data Primer, 2019 
Dari table 1 dapat ditarik kesimpulan dengan analisis fishbone sebagai berikut:

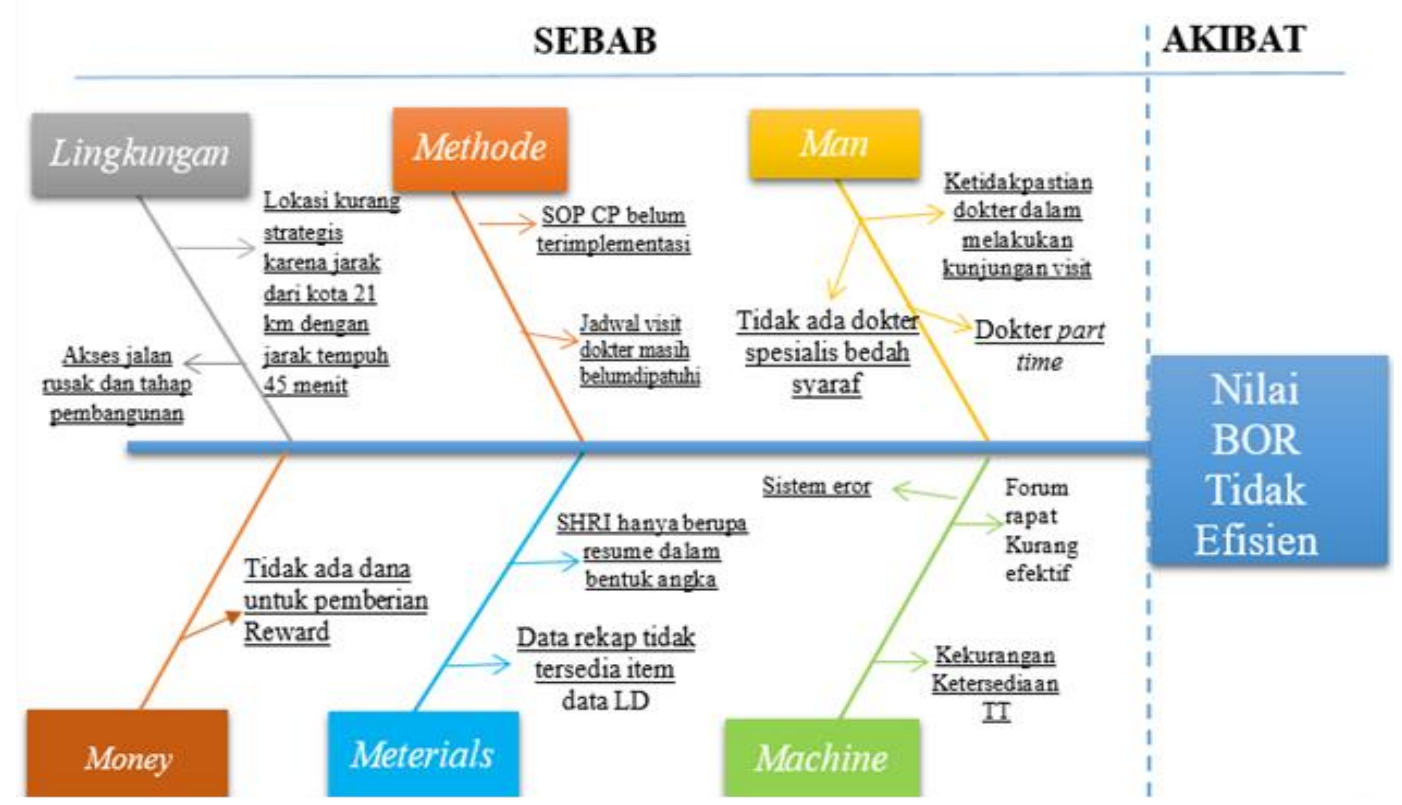

Gambar 2. Diagram Fishbone Faktor Determinan Efisiensi BOR

\section{PEMBAHASAN}

Faktor Methode (Metode) Penyebab Nilai Bed Occupancy Ratio Tidak Efisien Dari hasil kegiatan diatas apabila ditinjau dari aspek methode Penyebab Nilai Bed Occupancy Ratio Tidak Efisien dikarenakan jadwal visit dokter belum dipatuhi, dan belum terimplementasinya SOP terkait clinical pathway. Berdasarkan UU No 44 Tahun 2009 tentang Rumah Sakit pasal 32 poin e salah satu hak pasien yaitu memperoleh layanan yang efektif dan efisien sehingga pasien terhindar dari kerugian fisik dan materi. Dengan masih dijumpai jadwal visit dokter belum dipatuhi maka dapat berdampak pada tidak terpenuhinya hak pasien tersebut. Didukung hasil wawancara dengan responden yang menyatakan bahwa jadwal visit dokter telah diatur yaitu jam $08.00-$ 14.00 namun dalam implementasi masih ada yang di luar jadwal yang telah ditetapkan, sehinggan menghambat pelayanan lainnya khususnya di pendaftaran rawat inap terkait proses pesan kamar. Clinical pathway adalah syarat utama kendali mutu dan kendali biaya terutama pada kasus yang berpotensi menghabiskan sumber daya besar. Dalam penelitiannya membuktikan adanya penurunan ratarata lama dirawat pasien Skizofrenia setelah imlepementasi clinical pathway. Sehingga meningkatkan angka efektifitas pelayanan rawat inap mulai dari sumber daya manusia, penggunaan obat dan fasilitas lainnya (Nurfarida, 2014). Sosialisasi terkait SOP Clinical pathway di RSUD Kota Surakarta sangat dibutuhkan sehingga terwujud kepatuhan tenaga medis dalam penerapan perawatan dan mengisi form clinical pathway. Untuk meningkatkan mutu pelayanan demi tercapai derajat kesehatan yang semaksimal mungkin dan Nilai BOR sesuai dengan standard yang ditetapkan.

Faktor Mechine (Mesin) Penyebab Nilai Bed Occupancy Ratio Tidak Efisien. Penyebab Nilai BOR Tidak Efisien berdasarkan hasil kegiatan dikarenakan kurangnya fasilitas penunjang pelayanan kesehatan salah satunya yaitu ketersediaan TT. Sehingga mengakibatkan pasien 
dirujuk ke fasilitas pelayanan kesehatan lainnya, sehingga berakibat pada tingkat efisiensi penggunaan tempat tidur pasien rawat inap. Hal ini sejalan dengan penelitian Mardian yang menyatakan bahwa Sumber Daya Manusia yang kurang, sarana dan prasarana yang kurang memadai merupakan penyebab utama rendahnya angka kunjungan yang berakibat pada tingkat penggunaan tempat tidur yang tidak efisien. Untuk menunjang ketersediaan TT di RSUD Kota surakarta memerlukan pengkajian lebih dalam terhadap bangsal yang membutuhkan TT tambahan dengan relokasi TT bangsal lain yang sering kosong. Khususnya pada bangsal dewasa atau anak agar nilai BOR dapat mencapai angka efisien sesuai standar yang telah ditetapkan. Sehingga relokasi bisa dilakukan dari TT bangsal mawar atau nifas yang sering kosong karena pasien musiman, menjadi TT untuk bangsal anggrek atau penyakit anak yang lokasiny sama di lantai 2 (Mardian, 2016).

Terjadinya system error yang mengakibatkan pasien menumpuk dikarenakan tidak ada kebijakan untuk melakukan pendaftaran secara manual. Sehingga berakibat pasien dalam pengurusan administratif lebih lama karena harus menunggu sistem siap digunakan kembali. Hal ini sesuai dengan penelitian Hanna yang menyatakan bahwa faktor input yang lama dalam proses pelayanan merupakan salah satu penyebab rendahnya nilai BOR di Unit Stroke Center RS Islam Jakarta. Hal ini juga didukung dengan hasil wawancara yang menyatakan bahwa jika terjadi system error maka pendaftaran pasien akan dihentikan sampai pihak IT membenarkan agar sistem dapat beroperasi lagi. Sehingga memakan waktu yang lama. Agar pendaftaran tetap berjalan meskipun system error dan pasien tidak menunggu lama maka diperlukannya membuat dan menerapkan kebijakan untuk pendaftaran manual apabila terjadi system error. Dengan adanya kebijakan ini diharapkan mampu meningkatkan kualitas pelayanan dalam proses administratif (Hanna, 2015).

Penyebab lainnya dikarenakan

forum komunikasi, monitoring dan evaluasi antar pemberi pelayanan kesehatan khususnya perawat dan dokter terkait implementasi clinical pathway tidak dilakukan secara rutin. Dikarenakan sulitnya menjadwalkan dokter pemberi asuhan yang bekerja secara part time. Hal ini sama dengan penelitian Lestari yang menyatakan bahwa salah satu aspek fishbone berupa tidak adanya wadah komunikasi termasuk kedalam faktor machines (Lestari, 2017).

Faktor Man (Sumber Daya Manusia) Penyebab Nilai BOR Tidak Efisien. Dokter part time merupakan salah satu penyebab Nilai BOR Tidak Efisien. Dokter part time tersebut sesampainya dirumah sakit masih menangani pasien rawat jalan baru menuju ke bangsal. Dikarenakan banyaknya pasien yang telah ditangani sesampainya dibangsal dokter sudah kelelahan. Sehingga melakukan visit pada jam siang waktu pergantian shif terutama untuk pasien bedan dan dalam. Menurut hasil penelitian Hanna bahwa faktor yang mempengaruhi BOR adalah waktu visit dokter. Untuk itu perlu mengkomunikasikan kembali kepada pihak komite medis terkait penambahan dokter full time pada untuk spesialis bedah syaraf dan penyakit dalam agar nilai BOR dapat mencapai angka efisien sesuai standar yang telah ditetapkan (Hanna, 2015).

Faktor Materials (Bahan) Penyebab Nilai BOR Tidak Efisien. Penyebab Nilai BOR Tidak Efisien berdasarkan faktor materials yaitu dikarenakan tidak tersedianya item data LD pada rekapitulasi bulanan SHRI, dan pencatatan SHRI hanya berisi resume kegiatan 1 hari dalam bentuk angka. Hal ini belum sesuai dengan Depkes tentang cara pengisian SHRI harus memuat data pasien yaitu nama, nomor rekam medis dan diagnosis pada setiap perpindahan pasien. Sementara untuk pasien keluar harus mencantumkan tanggal 
masuk, tanggal keluar, kelas perawatan dan cara pasien keluar. Format isi dari Rekapitulasi bulanan SHRI khususnya pada kolom 12 harus memuat LD. Sehingga diharapkan rumah sakit mampu menyesuaikan kebijakan yang telah ditetapkan oleh Departemen Kesehatan Republik Indonesia, dengan melengkapi item data yang belum ada melalui revisi format formulir SHRI dan rekapitulasi bulanan SHRI. Dengan adanya revisi format SHRI yang dapat merekam data $\mathrm{LD}$ untuk dijadikan sumber acuan dalam penetapan Clinical Pathway dalam pelayanan perawatan pasien yang efektif dan efisien (Kesehatan, 2005).

Faktor Money (Dana) Penyebab Nilai BOR Tidak Efisien. Belum dianggarkannya dana dalam pemberian reward dan punishment di rumah sakit umum daerah kota surakarta merupakan salah satu penyebab BOR tidak efisien berdasarkan faktor Money. Berdasarkan hasil wawancara dengan petugas rekam medis bahwa rumah sakit sudah menjalankan program "Bintang Visit Dokter" berupa pemberian bintang kepada dokter. Bintang tertinggi yaitu 5 dengan beberapa kriteria, semakin konsistenan dan tepat jam visit dokter semakin banyak pula bintang yang dimiliki dokter tersebut begitu sebaliknya. Menurut Sofyandi pemberian reward kepada karyawan akan memberikan pengaruh yang signifikan terhadap kinerja. Mempertahankan karyawan agar terus datang untuk bekerja, dan memberikan motivasi kepada karyawan untuk mencapai tingkat kinerja yang tinggi (Sofyandi, 2014). Salah satu peran penting dari disciplinary punishment adalah memelihara kedisiplinan karyawan. Dengan sudah berjalannya pemberian bintang ini akan lebih baik lagi jika penganggaran dana untuk pemberian reward segera dapat terlaksana untuk memotivasi dokter dan pemberi asuhan keperawatan untuk meningkatkan kinerja dan pelayanan prima guna tercapai nilai
BOR sesuai dengan standart yang ditetapkan (Hasibuan, 2015).

Faktor Lingkungan Penyebab Nilai BOR Tidak Efisien. Penyebab BOR tidak efisien dari hasil kegiatan yang ditinjau dari faktor lingkungan dikarenakan akses jalan dan lokasi yang kurang strategis. Akses jalan yang rusak dan masih dalam tahap pembangunan, serta lokasi yang harus masuk ke gang kecil atau jauh dari jalan utama. Kondisi tersebut mempengaruhi angka kunjungan pasien rawat inap yang berdampak pada nilai BOR tidak memenuhi standart. Hal ini didukung dengan hasil wawancara yang menyatakan bahwa kondisi lingkungan yang mempengaruhi angka kunjungan pasien rawat inap dikarenakan jalan rusak, tempat kita harus masuk di gang kecil. Sehingga pasien memilih ke rumah sakit yang ditepi jalan.

Diagram Fishbone Penyebab Nilai BOR Tidak Efisien. Diagram fishbone menggambarkan secara mudah tentang sebab akibat dari Nilai BOR tidak efisien. Berdasarkan hasil observasi dan wawancara terhadap 6 (enam) unsur yaitu method, machine, man, meterials, dan money, serta lingkungan. Dari diagram fishbone dapat diketahui bahwa faktor yang semakin mendekati kepala ikan merupakan faktor penyebab yang paling besar untuk terjadinya masalah yaitu nilai BOR tidak efisien. Penyebab tidak efisien nilai BOR berdasarkan urutan penyebab terbesar dipengaruhi oleh faktor man, mechine, materials, methode, lingkungan, dan money. Faktor man berupa dokter part time, ketidakpastian dokter dalam melakukan visit, dan tidak ada dokter spesialis bedah syaraf. Ketidakpastian dokter dalam melakukan visit, hal ini menyambung dengan faktor methode dikarenakan jadwal visit dokter belum dipatuhi. Berhubungan juga dengan faktor money dikarenakan belum dianggarkannya dana dalam pemberian reward dan punishment. 


\section{SIMPULAN}

Faktor - faktor yang mempengaruhi nilai BOR tidak efektif meliputi Methode (metode) (jadwal visit dokter belum dipatuhi dan SOP terkait CP belum terimplementasi), Machine (mesin) (kekurangan ketersedian TT, system error, dan forum rapat kurang efekif), Man (sumber daya manusia) (kurang dokter spesialis bedah syaraf, ketidakpastian dokter dalam melakukan kunjungan visit, dokter part time), Materials (bahan) (data rekapitulasi tidak tersedia item data $\mathrm{LD}$, SHRI hanya berisi resume kegiatan 1 hari dalam bentuk angka), Money (dana) (Belum ada dana untuk pemberian reward), lingkungan (akses jalan rusak dan lokasi kurang stategis). Diagram fishbone Nilai Bed Occupancy Ratio tidak efisien tebanyak disebabkan oleh faktor Man (sumber daya manusia) dan faktor Machine (mesin).

\section{DAFTAR PUSTAKA}

Hanna, H. (2015). Analisis faktor-faktor pelayanan yang mempengaruhi Bed Occupancy Rate (BOR) Unit Stroke Center RS. Islam Jakarta (tahun 2010 - 2013). Universitas Indonesia

Hasibuan. (2015). Manajamen Sumber Daya Manusia. Jakarta: PT. Bumi Aksara.

Kemenkes. (2018). Profile Kesehatan Indonesia Tahun 2017. Ministry of Health Indonesia (2017th ed.). Jakarta: Kementrian Kesehatan Republik Indonesia. https://doi.org/10.1002/qj

Kesehatan, D. (2005). Buku Petunjuk Pengisian, Pengolahan, dan Penyajian Data Rumah Sakit. Jakarta: Departermen Kesehatan Republik
Indonesia.

Lestari. (2017). Faktor-faktor Penyebab Ketidaklengkapan Dokumen Rekam Medis Pasien Rawat Inap Berdasarkan Metode Fish Bone di RSUD dr.Soeratno Gemolong. STIKes Mitra Husada Karang Anyar.

Mardian, A. (2016). Analisis Efisiensi Pelayanan Rawat Inap Rumah Sakit Daerah Balung Tahun 2015. Universitas Airlangga Surabaya.

Nofitasari. (2017). Faktor Penyebab Bor (Bed Occupancy Rate) Rendah Di Rumah Sakit Mitra Paramedika Tahun 2016. STIKes Jenderal Achmad Yani Yogyakarta. STIKes Jenderal Achmad Yani Yogyakarta.

Nurfarida. (2014). Efektivitas Pelayanan Selama Penerapan Clinical Pathway Skizofrenia Rawat Inap di RSUP Dr. Sardjito Yogyakarta. Jurnal Manajemen Pelayanan Kesehatan, 17(1).

Phillips, J., \& Simmonds, L. (2013). Using fishbone analysis to investigate problems. Nursing Times, 109(15), $18-20$.

Sidiq, R., \& Afrina, R. (2017). Kajian Efisiensi Pelayanan Rumah Sakit. Idea Nursing Journal, 8(1), 29-34.

Sofyandi, H. (2014). Manajemen Sumber Daya Manusia. Yogyakarta: Graha Ilmu.

Sudra. (2010). Statistik Rumah Sakit. Yogyakarta: Graha Ilmu.

Susilo, E., \& Nopriadi. (2012). Efisiensi Pendayagunaan Tempat Tidur dengan Metode Grafik BarberJohnson di Rs Lancang Kuning. Jurnal Kesehatan Komunitas, 1(4), 181-187. https://doi.org/10.25311/jkk.vol1.iss4. 24 